\title{
Analysis of Engineering Technology Students' Digital Footprints in Synchronous and Asynchronous Blended Courses
}

\author{
https://doi.org/10.3991/ijep.v12i1.24571 \\ Philip Appiah-Kubi ${ }^{1}\left({ }^{凶}\right)$, Khalid Zouhri ${ }^{1}$, Emily Basile ${ }^{2}$, Melissa McCabe ${ }^{1}$ \\ ${ }^{1}$ University of Dayton, Ohio, USA \\ ${ }^{2}$ FactSet Research Systems, Norwalk, USA \\ pappiahkubileudayton.edu
}

\begin{abstract}
The COVID-19 pandemic created an enormous challenge to academic institutions in the United States and around the world. Most higher education institutions in the United States shut down campuses and completed the second half of the spring 2020 semester virtually. During the fall 2020 semester, some institutions started with face-to-face classes but had to switch to virtual learning after noticing an increase in positive cases. Others adopted a blended approach to supplement face-to-face meetings. None of these approaches necessarily resolved the challenges faced by Engineering Technology programs which typically incorporate more laboratory and other hands-on modules in their curriculum. Due to the applied nature of Engineering Technology programs, it is important even in the era of COVID-19 to ensure that students stay engaged in creative ways to learn by doing. Consequently, this a posteriori study was initiated to learn about the level that Engineering Technology students engaged with online course materials during the spring and fall 2020 semesters. Thus, the lessons learned can be applied to future courses that incorporate blended learning. This paper reviews students' patterns of interactions with course videos to assess their relationship with the academic success of the students in some upper-level blended courses. It was observed that the students who performed better in the courses demonstrated at least a $44 \%$ level of engagement with course materials.
\end{abstract}

Keywords—blended learning, synchronous, COVID-19, asynchronous learning, student engagement

\section{Introduction}

The COVID-19 pandemic has created many necessary transitions and adjustments in all aspects of life. Many have questioned whether these changes will be permanent, or remain somewhat present, post-pandemic. A major change is the effect that the pandemic has had on the entire education system. Higher Educational practices in the era of COVID-19 look vastly different and questions have been raised about the future of these practices. While the adjustments were necessary for the safety of stu- 
dents and faculty members, some elements may remain in the fabric of higher education. For example, the pandemic forced instructors in Engineering and Engineering Technology programs to record classes and some lab sessions to enable undergraduate students the opportunity to playback the lecture. This was the case of the courses reviewed in this paper. Traditionally in-person courses (face-to-face) had to swiftly switch the delivery mode to blended. Likewise, the pandemic forced schools around the world to shift from the traditional face-to-face classroom setting to a virtual or online setting, or even a blended learning environment that combines aspects of both [1-3]. It is only imperative that instructors review and identify important lessons that can be used to supplement future course deliveries. That is the motivation for this study.

From K-12 through higher education, institutions have had to respond quickly to the situations created by the pandemic to support academic activities during the second half of spring 2020, summer, and fall 2020. This is expected to extend beyond spring 2021 and probably through the next summer. Even though there is a vaccine breakthrough, the timeline to achieve herd immunity is not certain. Hence, institutions still have to identify ways to remain competitive and provide an effective and productive educational experience for students. It is therefore not surprising that colleges utilized similar course modalities in spring 2021. For example, the University of Dayton categorized some courses as blended, remote-friendly, and face-to-face with COVID-19 related safety protocol observations.

The impact of the pandemic on academic programs and the disruptions to traditional teaching and learning modes can be felt by all academic programs that utilized the traditional brick-and-mortar structure for instructor-student interactions. One such program is Engineering Technology (ET) which focuses more on application. The hands-on nature of ET programs meant that instructors had to be more creative at providing a tangible and palpable experience for ET students even if it is delivered virtually. This is one of the reasons why blended courses, which deliver some course content virtually and the remaining as in-person (face-to-face), were prioritized for face-to-face learning at the Engineering Management, Systems and Technology department at the University of Dayton. This allowed students the chance to still get the extremely important laboratory experience that ET curricula provide. However, the success of this model depends on students' and instructors' ability to remain negative of the virus and also for the entire campus to maintain a relatively low positivity rate.

With all the challenges colleges face, instructors still had to plan to complete their courses should face-to-face meetings be canceled. Consequently, ways to deliver a virtual experience for ET students must be explored to identify the courses that cannot be offered completely virtual. For the remaining courses, it is important to ensure that the students remained engaged with the virtual content even if they are not necessarily laboratory-based to understand the applied nature of the ET courses. Hence, ET faculty members must review the level of student engagement in synchronous and asynchronous online courses to enhance the chances of reaping the full benefits of blended learning. In this paper, the level of engagement is defined as the percentage of time that a class recording was reviewed or played by a student. 


\section{Literature review}

\subsection{What is blended learning?}

Blended learning is a combination of online and face-to-face classroom learning [4]. Blended learning takes advantage of both settings since the lack of personal contact with peers and faculty in online learning is compensated for by the face-to-face sessions. Likewise, the lack of self-paced learning in face-to-face teaching is compensated for by the online environment [4]. Typically, there are three general formats for blended learning: use an online session as preparation for a face-to-face session later in the week, invert this format so that the online session is used as a follow-up after a face-to-face session, or utilize online elements during a face-to-face session, for example working in simulated environments [4].

\subsection{Benefits of blended learning}

The study, "Blended Learning: Balancing the Best of Both Worlds for Adult Learners," describes many benefits of using a blended learning environment. McKenna et al. at Colorado State University completed a two-phase study to investigate the best way to deliver blended learning for their students [5]. Two blended learning approaches were used: face-to-face learning combined with asynchronous online classes during the fall semester, and fully face-to-face classes alternated weekly with fully asynchronous online classes during the spring semester [5]. Christina Andersson and Doina Logofatu utilized blended learning to enhance the teaching of statistics for computer science and engineering students [6]. The study showed that not only does blended learning improve adult learning outcomes, but it is preferred over exclusively online or face-to-face classes due to its flexibility [5]. It is no surprise that if a student prefers one learning style over another, that their overall interest, effort, and performance would be better than if they were using a style of learning they do not prefer. The study also found that blended learning, fully face-to-face, and fully online learning had the same or very close course outcomes [5]. This evidence shows that no one format lacks or outperforms another in ensuring course outcomes are met.

Research shows there is an overwhelmingly positive student perception for blended or online learning in comparison to a traditional face-to-face classroom. The study, "E-Learning amid the COVID-19 Lockdown: Standpoint of Medical and Dental Undergraduates," [7] used a descriptive online questionnaire to gather responses of student views on online learning. About three hundred medical and dental students of CMH Lahore Medical College were used for the study [7]. Results showed that students believe online learning has increased their motivation and made them more engaged with the course content, and that online lectures were more organized than traditional face-to-face lectures. Students also revealed that online teaching had greater availability of resources which provided them with a better understanding of the course content $[3,4,5]$. Because of the greater availability of resources, students also noted that online study materials provide flexibility in the learning process and in general, save them time [7]. 
Another study titled, "Learning From the Learners: Student Perception of the Online Classroom," [10] drew similar conclusions. This study provided seven openended discussion questions to two hundred and twenty-nine business graduate students to understand their perceptions and experiences using online learning [10]. The students described that the online classroom, for asynchronous class sessions, is essentially "open $24 / 7$ " which is extremely convenient for students in comparison to the traditional classroom that is only open during a fixed time and at a fixed location. Students also noted that classroom discussions during synchronous class sessions are recorded and available to re-open for future use, which is a luxury that traditional face-to-face class sessions do not have [10]. Relying on the memory or the notes taken during class does not completely record every piece of the content discussed compared to accessible online class recordings. Students also noted how the online classroom has low opportunity costs, aside from internet access and a computer, in comparison to the commuter costs or babysitter fees that come with attending class in person [10].

Another study, "Schooling and Education in Times of the COVID-19 Pandemic: Food for Thought and Reflection Derived From Results of the School Barometer in Germany, Austria, and Switzerland," [11] found that blended learning will benefit all actors in the education system through developing and taking advantage of this digitalization movement. The study collected responses from the school barometer online survey in Austria, Germany, and Switzerland with around twenty-four thousand students, parents, school staff, and school leaders [11]. The study highlights the importance and benefits of learning with and through technology, as well as about technology [11]. The author explains that capitalizing on the advantages of having to use blended learning during the COVID-19 pandemic can help students transition from school to work from a digitalization standpoint [11]. Having prior knowledge on how 'Skype,' 'Microsoft Teams,' or 'Zoom' works allows for students to already have the necessary skills to utilize those programs in a professional setting.

Learning new software can also help students prepare for job training that often requires going through a similar process of learning a company's software. Similarly, school systems should focus on personnel development, organizational development, and academic development during this time [11]. The many benefits of blended learning described in this paper are being acknowledged by both students and faculty. Because of the positive reactions, the technology being utilized to overcome today's pandemic may continue to be used in the longer term.

\subsection{Challenges of blended learning}

Though there are many benefits to blended learning, the importance of the physical presence of teachers in the traditional learning environment cannot be undermined. A study titled, "Quarantine: Teaching English From Home with Google Classroom, Classtime, and Quizlet," revealed some challenges that occur within a blended learning environment. The study created a survey that measured students' attitudes to online learning in general, and utilizing the online education tools 'Google Classroom,' 'Classtime,' and 'Quizlet.' The survey indicated that about half of the re- 
spondents $(54 \%)$ were not sure that online learning is more effective than face-to-face learning, nearly a quarter $(23 \%)$ agree that online learning is more effective than faceto-face learning, while others either disagree (14\%) or strongly disagree $(11 \%)$. The study noted that students who selected disagree or strongly disagree may have done so as a result of the urgency for online learning due to COVID-19. The biggest issues that students saw with online learning were miscommunication $(34 \%)$ and lack of information (34\%). Poor or unstable Internet connection was the next biggest issue (29\%) [12]. Online education tools such as 'Google Classroom' provide a platform to store lecture recordings, submit assignments, and provide grading feedback. Though they lack direct communication between faculty and students, utilizing 'Skype' or 'Zoom' can compensate for that loss [12].

In the aforementioned study, the author highlighted many benefits of blended learning. Berry also described a few challenges, for example, the flow of conversation is much slower as a result of people who are not all in the same place at the same time. Due to inevitable technological issues, there is the potential for noises interfering with the transmission of messages during both synchronous and asynchronous class sessions [10]. Similarly, Holzweiss et al. explain that face-to-face courses have an automatic connection of physical presence, meaning that faculty can interpret students' non-verbal cues and communicate in real-time with their reactions. This skill is extremely difficult to use over applications such as 'Skype' or 'Zoom' when students' microphones or even cameras are turned off [13]. Though some argue that students are more willing to participate in online classes versus traditional face-to-face classes, this study revealed that in online classes, faculty have to depend on direct communication from students since they do not have physical signals, and direct communication is not always forthcoming [13]. Roache came to a similar conclusion that it is a challenge for professors to provide an environment that involves interaction and collaboration over online platforms [14].

Lastly, online or blended learning can be challenging for international students. Liu et al. explain that lack of visual cues, scheduling issues, and time zone differences are major problems for students whose primary language is not native to the professors', or for students who are not in the same time zone as that of the professor or school [15]. If a professor does not have their camera on while lecturing, communication barriers occur for students who need to watch the professor speak to better understand what they are saying. Scheduling meeting times for group projects poses difficulties due to time zone differences. Likewise, students in drastically different time zones suffer from attending synchronous class sessions at extremely inconvenient times.

\subsection{Student engagement}

Student engagement is defined as "a meaningful engagement throughout the learning environment" [16]. Student engagement has an enormous impact on the general performance of students. It is one of the major factors that can impact the student dropout rate. Frederick [17] identified that improved student engagement can help prevent boredom and alienation, and also leads to higher achievement and a low dropout rate. 
Students' academic performance improves if they are engaged [18]. Appleton, Christenson, and Furlong observed that student behavior is positively enhanced when they are engaged. To harness the benefit of student engagement, all stakeholders in students' development need to play a critical role. Parents, students, instructors, and academic institutions must function effectively to ensure that the benefits can be fully achieved [16]. Even though all the stakeholders play a crucial role in developing and sustaining student engagement, instructors are in a pivotal position since they have greater control through their daily or weekly interactions with their students. A poorly delivered course may lead to less student engagement. Umbach and Wawrzynski [19] observed that the behaviors and attitudes with which faculty members deliver their courses and the context created by them significantly impact student engagement. The interactions between faculty members and students are arguably the most important factor that influences student learning [19].

Groves [20] also emphasizes the importance of student engagement and the critical role it plays in academic success. The students who are engaged in their classes through their relationship with the faculty members, as well as the course materials, generally perform better in the courses [20]. If institutions can support faculty members through professional development, and by providing the resources needed to develop engaging course content, students stand a greater chance of succeeding [21]. It was therefore not surprising that most institutions, without prior notification, decided to utilize services such as 'Zoom' to record lectures and make them accessible to students during the peak of the COVID-19 pandemic. Since the pandemic created a lot of stressors for both faculty members and students, it may be viewed as a win-win for faculty members to have the ability to record their lectures, and also for students to have the convenience of playing back recordings. However, there is no guarantee that students will utilize lecture recordings. It is therefore important for faculty members to periodically review student engagement with class material especially if faceto-face meetings are limited.

The next section presents the results of the Engineering Technology students' level of engagement in three Engineering Technology courses which were taught during the Spring 2020 and Fall 2020 semesters at a four-year college. It focuses only on the course contents that were delivered virtually to Engineering Technology students.

\section{$3 \quad$ Results and discussions}

The Global Supply Chain Management (GSM) course is designated as a junior/senior-level course and it is open to ET and Engineering students. Besides Industrial Engineering Technology students who take it as a required course, all other students take it as an elective. During the spring 2020 semester, students utilized Excel and Lingo to solve quantitative supply chain problems. There was no individual or team project. The course was face-to-face until mid-semester when classes went virtual.

During this time about $90 \%$ of the remaining course content was delivered synchronously on Zoom. The Project Management (PM) course, which is also taken by 
juniors and seniors, followed a similar approach as the Global Supply Chain Management course with about $92 \%$ of the remaining course content delivered synchronously on Zoom during the Spring 2020 campus shutdown. Both client-based projects and non-client-based projects were randomly assigned to teams of 3 to 4 students to be completed in the last 8 weeks of the semester. Two quizzes and an exam each were completed in both classes during the virtual section of the Spring 2020 semester. The Data Analytics (DA) course was blended for the entire semester (Fall 2020) and had graduate and undergraduate students who each completed a term project as part of the course requirements. In addition, a total of four quizzes and two exams were also completed in this course. Even though the course was blended, short SPSS videos were posted on the Learning Management System (LMS) for students to review and reference when completing assignments.

The Global Supply Chain Management class in spring 2020 had 31 students. Among these were 17 Industrial Engineering Technology (IET) majors, 11 Mechanical Engineering Technology majors, 1 Electronic and Computer Engineering Technology major, 1 Psychology major, and 1 exchange program student. This paper focuses only on the Engineering Technology (ET) students. Twenty-two (22) of the students were seniors with the rest being juniors. For the majority of the semester, students met at class time synchronously with the instructor. The Data Analytics and the Project Management classes respectively had 14 and 27 undergraduate Engineering Technology students who were all seniors.

For each video posted for asynchronous learning, the LMS collects information about students' levels of engagement. This is defined as the proportion of time that a student played the class recordings. The average level of engagement, average quiz score, and exam (non-comprehensive) score for the spring 2020 course (virtual section only), and that of fall 2020 for the engineering technology students were collected for this study. Table 1 shows the descriptive statistics of the level of engagement.

Table 1. Descriptive statistics of student engagement

\begin{tabular}{|l|c|c|c|c|}
\hline \multicolumn{1}{|c|}{ Course } & N & Mean & Std. Deviation & Std. Error \\
\hline PM & 27 & 72.41 & 21.13 & 4.07 \\
\hline GSM & 29 & 71.69 & 23.83 & 4.43 \\
\hline DA & 14 & 63.50 & 21.41 & 5.72 \\
\hline
\end{tabular}

Even though the DA class had a relatively low level of engagement, the Analysis of Variance (ANOVA) test (with equal variances assumed) was used since three means with equal variances were being compared [22]. It resulted in no statistically significant difference in the mean level of engagement $(F(2,0.824, p$-value $=0.443)$. However, the average (Table 2) quiz and exam scores were statistically significantly different. For the quizzes, the homogeneity of variances assumption was violated, hence, the Welch F-ratio $F(2,42.374)=17.762$, $p$-value $=0.000)$ indicates a statistically significant difference in means. A Games-Howell post-hoc test revealed that the PM and DA were significantly different $(p<0.05)$ as well as DA and GSM $(p<0.05)$. There was no difference between PM and GSM. A similar observation can be noted 
about the exam scores. With heterogeneous variances, Welch F-ratio ( $F(2$, $44.465)=9.489, p$-value $=0.00$ ) indicates a statistically significant difference in the means (Table 3). The Games-Howell post-hoc test revealed that the DA exam score was statistically significantly different from that of the PM. The others were not statistically significantly different.

Table 2. Descriptive statistics of quiz scores

\begin{tabular}{|l|c|c|c|c|}
\hline & N & Mean & Std. Deviation & Std. Error \\
\hline PM & 27 & 78.37 & 14.85 & 2.86 \\
\hline GSM & 29 & 81.11 & 12.52 & 2.33 \\
\hline DA & 14 & 92.12 & 3.48 & 0.93 \\
\hline Total & 70 & 82.25 & 13.24 & 1.58 \\
\hline
\end{tabular}

Table 3. Descriptive statistics of exam scores

\begin{tabular}{|l|c|c|c|c|}
\hline & N & Mean & Std. Deviation & Std. Error \\
\hline PM & 27 & 84.92 & 7.030 & 1.35 \\
\hline GSM & 29 & 90.28 & 9.02 & 1.67 \\
\hline DA & 14 & 92.12 & 3.48 & 0.93 \\
\hline Total & 70 & 88.58 & 7.93 & 0.95 \\
\hline
\end{tabular}

Furthermore, the students' exam and quiz scores were categorized into two groups: "did well" in class and "did not do well". If a student's final grade from the exams and quizzes was $80 \%$ (B-) and above, the student was categorized as "did well." Bwas chosen as the benchmark because that was the lowest grade students expected for themselves when asked at the beginning of the semester. However, Figure 1 shows that among the students who did well, the level of engagement (on the horizontal axis) ranged from $44 \%$ to $98 \%$. Similarly, a lot of students also demonstrated higher levels of engagement but did not necessarily do well. This means that even though some level of engagement may lead to better performance, it does not guarantee success since class performance in asynchronous lessons requires several variables that must work harmoniously to suit the students' learning styles. 


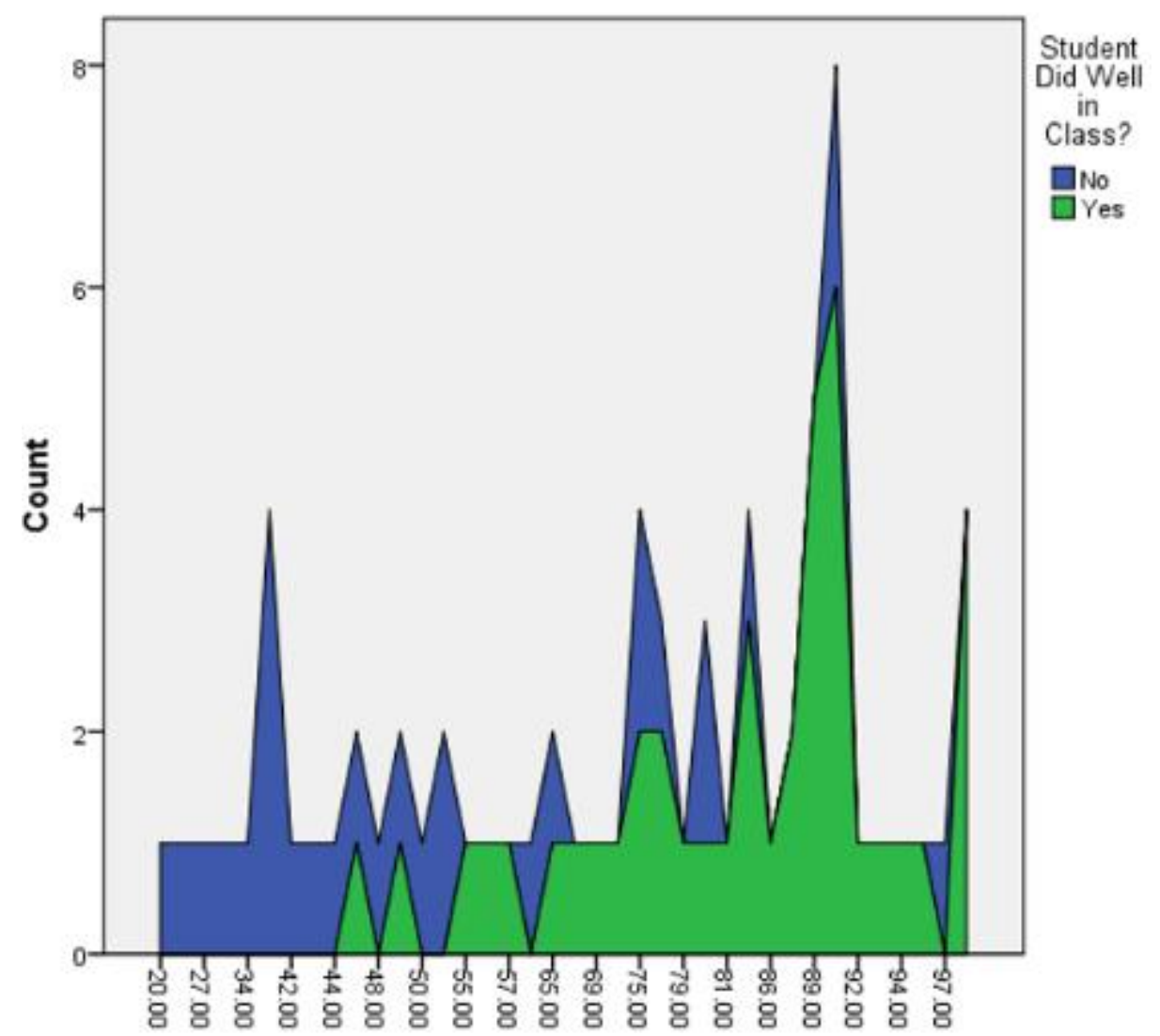

Fig. 1. Level of engagement

\section{Conclusion}

The COVID-19 pandemic has led to many necessary transitions and adjustments in higher education. Even though most academic programs required a swift response to sustain meaningful teaching and learning, engineering technology and other programs that thrive on face-to-face, hands-on, and experiential learning required a more thoughtful response beyond just going virtual on Zoom in order to make the learning experience worthwhile. Consequently, the digital footprint of students must be reviewed to determine the level of student engagement with course materials, especially in asynchronous classes. This paper observed in three engineering technology courses that the level of student engagement with virtual asynchronous course contents was not statistically significantly different. The level of engagement also did not appear to significantly influence students' performance in the courses. However, as seen in Figure 1, the students who did well demonstrated a minimum of $44 \%$ level of engagement with course contents. This means that some level of engagement (as ex- 
pected) is required to be successful in a virtual asynchronous class. However, engineering technology students' engagement and performance in virtual asynchronous courses depend on several factors that must be harmonized to deliver the desired results. Providing a balance between synchronous and asynchronous class sessions can allow for the necessary interaction amongst students while reaping the benefits of blended learning.

\section{$5 \quad$ Limitation of the study}

This research relies on limited data from three Engineering Technology courses taught over two semesters in one year. The class sizes were also small; hence, further research is required to generalize the observations from this study. In addition, it was a posteriori study; hence, a more robust scientific study may be required to validate the findings from this study.

\section{References}

[1] Biwer F, Wiradhany W, oude Egbrink M, Hospers H, Wasenitz S, Jansen W and de Bruin A (2021) Changes and Adaptations: How University Students Self-Regulate Their Online Learning During the COVID-19 Pandemic. Front. Psychol. 12:642593. https://doi.org/ $10.3389 /$ fpsyg. 2021.642593

[2] Nasim Muhammad, and Seshasai Srinivasan, "Online Education During a Pandemic- Adaptation and Impact on Student Learning”. International Journal of Engineering Pedagogy. 2021, Vol. 11 Issue 3, p71-83.

[3] Padrul Jana, Nurchasanah, "E-Learning During Pandemic Covid-19 Era Drill Versus Conventional Models". International Journal of Engineering Pedagogy. 2021, Vol. 11 Issue 3, p54-70. https://doi.org/10.3991/ijep.v11i3.16505

[4] Hege, Inga, et al. "Blended Learning: Ten Tips on How to Implement It into a Curriculum in Healthcare Education." GMS Journal for Medical Education, vol. 37, no. 5, Sept. 2020, pp. 1-12. https://dx.doi.org/10.3205\%2Fzma001338

[5] McKenna, Kelly, et al. "Blended Learning: Balancing the Best of Both Worlds for Adult Learners." Adult Learning, vol. 31, no. 4, Nov. 2020, pp. 139-149. https://doi.org/ $\underline{10.1177 \% 2 F 1045159519891997}$

[6] Christina Andersson and Doina Logofatu: "A Blended Learning Module in Statistics for Computer Science and Engineering Students Revisited". Vol 7, No 4 (2017).

[7] Anwar, Aiza, et al. "E-Learning amid the COVID-19 Lockdown: Standpoint of Medical and Dental Undergraduates." Pakistan Journal of Medical Sciences, vol. 37, no. 1, Jan. 2021, pp. 217-222. https://dx.doi.org/10.12669\%2Fpjms.37.1.3124

[8] Rohit Kandakatla, Edward J Berger, Jeffrey F. Rhoads, Jennifer DeBoer. "Student Perspectives on the Learning Resources in an Active, Blended, and Collaborative (ABC) Pedagogical Environment." International Journal of Engineering Pedagogy. Vol 10, No 2 (2020). https://doi.org/10.3991/ijep.v10i2.11606

[9] Obukhova Lyudmila A, Galustyan,Olga V, Baklanov Igor O, Belyaev Roman. "Formation of Organizational Competence of Future Engineers By Means of Blended Learning". International Journal of Engineering Pedagogy. 2020, Vol. 10 Issue 2, p119-127. https://doi. org/10.3991/ijep.v10i2.12047 
[10] Berry, Gregory R. "LEARNING FROM THE LEARNERS: Student Perception of the Online Classroom." Quarterly Review of Distance Education, vol. 19, no. 3, Sept. 2018, pp. 39-56.

[11] Huber, Stephan Gerhard. "Schooling and Education in Times of the COVID-19 Pandemic: Food for Thought and Reflection Derived From Results of the School Barometer in Germany, Austria and Switzerland." International Studies in Educational Administration (Commonwealth Council for Educational Administration \& Management (CCEAM)), vol. 49, no. 1, Jan. 2021, pp. 6-17.

[12] Saienko, Nataliia, and Oksana Chugai. "Quarantine: Teaching English From Home with Google Classroom, Classtime and Quizlet.” Romanian Journal for Multidimensional Education, vol. 12, June 2020, pp. 151-156. https://doi.org/10.18662/rrem/12.1sup2/258

[13] Holzweiss, Peggy C., et al. "Online Graduate Students' Perceptions of Best Learning Experiences.” Distance Education, vol. 35, no. 3, Nov. 2014, pp. 311-323. https://doi.org/ $\underline{10.1080 / 01587919.2015 .955262}$

[14] Roache, Darcia, et al. "Transitioning to Online Distance Learning in the COVID-19 Era: A Call for Skilled Leadership in Higher Education Institutions (HEIs).” International Studies in Educational Administration (Commonwealth Council for Educational Administration \& Management (CCEAM)), vol. 48, no. 1, Jan. 2020, pp. 103-110.

[15] Liu, Xiaojing, et al. "Cultural Differences in Online Learning: International Student Perceptions.” Journal of Educational Technology \& Society, vol. 13, no. 3, Oct. 2010, pp. $177-188$.

[16] Delfino, Armando P., "Student Engagement and Academic Performance of Students of Partido State University." Asian Journal of University Education, Vol 15, no. 3, 2019, pp $42-55$.

[17] Fredricks, J. A., Blumenfeld, P. C., \& Paris, A. H. "School Engagement: Potential of the Concept, State of the Evidence." Review of Educational Research, 74(1), (2004). 59-109. https://doi.org/10.3102/00346543074001059

[18] Appleton, J. J., Christenson, S. L., \& Furlong, M. J.. "Student engagement with school: Critical conceptual and methodological issues of the construct." Psychology in the Schools. Vol 45(5), (2008). Pp 369-386. https://doi.org/10.1002/pits.20303

[19] Umbach, P. D., \& Wawrzynski, M. R. "Faculty do Matter: The Role of College Faculty in Student Learning and Engagement." Research in Higher Education, 46(2), (2005).153-184. https://doi.org/10.1007/s11162-004-1598-1

[20] Groves, M., Sellars, C., Smith, J., \& Barber, A. Factors Affecting Student Engagement: A Case Study Examining Two Cohorts of Students Attending a Post-1992 University in the United Kingdom. International Journal of Higher Education, (2015). 4(2). https://doi. org/10.5430/ijhe.v4n2p27

[21] Coates, H. "A model of online and general campus-based student engagement." Assessment \& Evaluation in Higher Education, 32(2), (2007). 121-141. https://doi.org/10.1080/ $\underline{02602930600801878}$

[22] Field, A. Discovering statistics using IBM SPSS statistics (4th ed.). SAGE Publications. (2013).

\section{$7 \quad$ Authors}

Philip Appiah-Kubi, Ph.D., is an associate professor at the University of Dayton's Engineering Management, Systems and Technology Department. He has a Ph.D. in Industrial and Systems Engineering and a master's degree in Aviation Systems and 
Flight Testing from Ohio University and The University of Tennessee respectively. $\mathrm{He}$ also has a graduate certificate in Engineering Management. His research interests lie in the applications of data analytics, supply chain management, and engineering pedagogy.

Khalid Zouhri, Ph.D., is an assistant professor of mechanical engineering technology in the Department of Engineering Management, Systems and Technology at the University of Dayton. Before joining the faculty at UD, he was an assistant professor in the Department of Mechanical Engineering at Higher College of Technology. Before that Dr. Zouhri was an adjunct professor at the University of New Haven while working in the aerospace industry. Dr. Zouhri has over a decade of experience in the aerospace industry. Dr. Zouhri received his B.S. in mechanical engineering from North Carolina A\&T State University, MBA from Southern Connecticut State University and Ph.D. in mechanical engineering from Michigan Technological University. Some research interests of Dr. Zouhri's are nanomaterials characterizations, materials behavior at high temperature for propulsion systems, thermal and bio-fluid mechanics, and turbulence analysis.

Emily Basile is currently a Client Solutions Associate at FactSet Research Systems. She has a Bachelor's degree in Industrial Engineering Technology, and a Master's degree in Engineering Management, both earned at the University of Dayton. She also has graduate certificates in the Foundations of Engineering Management and Systems Engineering Management.

Melissa McCabe is a graduate student at the University of Dayton, currently working towards receiving her Master's degree in Engineering Management. She received her Bachelor's degree in Industrial Engineering Technology, also from the University of Dayton, in addition to a graduate certificate in Foundations of Engineering Management.

Article submitted 2021-06-05. Resubmitted 2021-10-21. Final acceptance 2021-10-22. Final version published as submitted by the authors. 